\title{
Peningkatan Kemampuan Mengatasi Masalah Stunting dan Kesehatan melalui Pemberdayaan Masyarakat Desa Sukogidri, Jember
}

\author{
Erma Sulistyaningsih ${ }^{1}$, Parawita Dewanti ${ }^{2}$, Pulong Wijang Pralampita ${ }^{2}$, \\ Wiji Utami² \\ 1,2 Universitas Jember, Indonesia
}

\begin{abstract}
A B S T R A C T
INCREASING THE ABILITY IN OVERCOMING STUNTING AND HEALTH PROBLEM BY COMMUNITY EMPOWERMENT IN SUKOGIDRI VILLAGE-JEMBER. Indonesia has a high prevalence of stunting, and Jember is one of the six districts in East Java province that contribute to stunting prevalence. To overcome the stunting problem, it needs a holistic strategy including health, education and economic aspects, therefore the community empowerment is an important approach. The purpose of this public service program was to increase the awareness and capability of the community to overcome stunting and health problem by community empowerment. Several activities were conducted in this community service program, i.e. by examining the health status of the children, pregnant woman, and high risk people, counseling and education about stunting and the effect on health status and also the effect for the next generation, education about the efforts to prevent stunting, provide training to prepare a healthy food and specific training for the cadres who responsible for the stunting-alleviation program. The impact of the activity was an increase the knowledge and awareness of the community about stunting. And there were several trained-cadres about stunting and its prevention.

Keywords: Community Empowerment, Health Problem, Jember, Stunting.

\begin{tabular}{llll}
\hline Received: & Revised: & Accepted: & Available online: \\
18.09 .2019 & 11.01 .2020 & 03.02 .2020 & 14.02 .2020 \\
\hline
\end{tabular}
\end{abstract}

\section{Suggested citation:}

Sulistyaningsih, E., Dewanti, P., Pralampita, P., \& Utami, W. (2020). Peningkatan kemampuan mengatasi masalah stunting dan kesehatan melalui pemberdayaan masyarakat Desa Sukogidri, Jember. Jurnal Pengabdian Pada Masyarakat, 5(1), 91-98. https://doi.org/10.30653/002.202051.244

Open Access I URL: http://ppm.ejournal.id/index.php/pengabdian/article/view/244

${ }^{1}$ Corresponding Author: Fakultas Kedokteran Universitas Jember; Jl. Kalimantan No. 37 Jember, Jawa Timur, Indonesia; Email: sulistyaningsih.fk@unej.ac.id 


\section{PENDAHULUAN}

Stunting atau kerdil adalah keadaan seorang balita yang memiliki panjang atau tinggi badan yang kurang jika dibandingkan dengan umur yang seharusnya. Stunting merupakan masalah gizi utama dunia termasuk Indonesia. World Health Organisation (WHO) menjadikan stunting sebagai fokus Global Nutrition Target 2025, dan program Sustainable Development Goals (SDGs) 2030 (WHO, 2019). Data dari Kementerian Kesehatan menunjukkan persentase stunting terus meningkat dari tahun 2014-2018, dari angka 28,9\% di tahun 2014, dan terus meningkat sampai 2018 sebesar 30,8\% (Kementerian Kesehatan, 2018). Angka ini masih lebih tinggi dari target WHO yang menetapkan angka stunting harus di bawah $20 \%$.

Balita stunting merupakan masalah gizi kronik yang kompleks, kondisi ini disebabkan oleh banyak faktor antara lain kondisi sosial ekonomi, gizi ibu saat hamil, kesakitan pada bayi, dan kurangnya asupan gizi pada bayi. Selain permasalahan kesehatan yang dialami saat itu, balita stunting di masa yang akan datang juga akan mengalami kesulitan dalam mencapai perkembangan fisik dan kognitif yang optimal (Pusat Data dan Informasi. Kementerian Kesehatan RI, 2018). Oleh karena itu, stunting merupakan permasalahan besar karena berpengaruh pada perkembangan generasi penerus bangsa.

Besarnya dampak yang dapat ditimbukan akibat stunting membuat pemerintah mencanangkan beberapa program intervensi untuk pencegahan dan penanganan stunting secara terintegrasi dengan melibatkan lintas kementerian dan lembaga. Pada tahun 2018, telah ditentukan lokus 160 kabupaten/kota penurunan stunting tahun 20182019. Jember menjadi 1 dari 6 kabupaten di Jawa Timur yang menjadi lokus penurunan stunting 2018-2019, dan Desa Sukogidri merupakan 1 dari 10 desa di Kabupaten Jember yang menjadi sasaran program penurunan stunting (Kementerian Kesehatan, 2018; Dinas Kesehatan Pemerintah Kabupaten Jember, 2018).

Pemerintah telah menetapkan strategi lima pilar penanganan stunting, yaitu (1) komitmen dan visi kepemimpinan, (2) kampanye nasional dan komunikasi perubahan perilaku, (3) konvergensi, koordinasi, konsolidasi program pusat, daerah dan desa, (4) gizi dan ketahanan pangan, dan (5) pemantauan dan evaluasi. Selain itu juga terdapat upaya percepatan penurunan stunting melalui intervensi gizi spesifik dan intervensi gizi sensitif (Kementerian Kesehatan, 2018). Aridiyah (2015) melaporkan bahwa beberapa faktor yang mempengaruhi terjadinya stunting pada balita di pedesaan dan perkotaan terutama di Kabupaten Jember adalah pendidikan ibu, pendapatan keluarga, pengetahuan ibu mengenai gizi, pemberian ASI eksklusif, umur pemberian MP-ASI, tingka kecukupan zink dan zat besi, riwayat penyakit infeksi serta faktor genetik. Banyaknya faktor yang berperan dalam menimbulkan kejadian stunting tentu memerlukan penanganan yang komprehensif melibatkan berbagai bidang. Kegiatan pengabdian kepada masyarakat ini secara umum bertujuan untuk mendukung program penanganan dan pencegahan stunting yang telah dicanangkan pemerintah. Sedangkan tujuan khususnya antara lain untuk meningkatkan kesadaran dan pengetahuan masyarakat mengenai stunting, dampak stunting terhadap kesehatan dan dampaknya pada masa depan, menambah wawasan tentang upaya pencegahan dan penanganan stunting. Diharapkan dengan kegiatan ini tercipta keberdayaan 
masyarakat dalam mengatasi masalah stunting yang sedang mereka hadapi sehingga masyarakat dapat turut serta menyelesaikan masalah stunting.

\section{METODE}

Kegiatan pengabdian kepada masyarakat ini dilakukan di Desa Sukogidri Kecamatan Ledokombo Kabupaten Jember. Desa ini terletak $35 \mathrm{~km}$ dari pusat Kabupaten Jember. Desa Sukogidri merupakan salah satu desa penyumbang angka stunting di Kabupaten Jember (Desa Sukogidri, 2017). Kegiatan pengabdian kepada masyarakat ini dilakukan secara bertahap dan menggunakan beberapa metode pada bulan Mei-Agustus 2019. Setiap kegiatan dilakukan dengan sasaran tertentu disertai dengan penentuan indikator keberhasilan dan upaya tindak lanjut yang dilakukan setiap tahapannya. Tahapan kegiatan pengabdian yang dilakukan dijabarkan berikut ini.

\section{Pengukuran status gizi dan status kesehatan}

Pengukuran status gizi dilakukan dengan sasaran balita, ibu hamil, calon ibu dan kelompok rentan gizi. Indikator keberhasilan kegiatan ini adalah didaptakan data status gizi kelompok-kelompok yang rentan gizi. Dari hasil kegiatan ini dapat dilakukan tindak lanjut berupa pemberian penyuluhan, makanan tambahan dan selanjunya dilakukan pemeriksaan ulang untuk mengetahui hasil tindak lanjut yang telah dilakukan.

Kelompok lain yang dilakukan pemeriksaan kesehatan adalah lansia, kelompok risiko tinggi dan kelompok usia produktif, dalam hal ini adalah kelompok petani karena sebagian besar penduduk Desa Sukogidri berada pada kelompok usia produktif dan sebagian besar berprofesi sebagai petani atau buruh tani. Indikator keberhasilan kegiatan ini adalah diketahuinya data dasar status kesehatan kelompok-kelompok tersebut sehingga dapat ditentukan tindak lanjut yang sesuai misalnya penyuluhan.

\section{Penyuluhan}

Materi penyuluhan yang diberikan adalah tentang stunting, bahaya atau efek stunting terhadap kesehatan, dampaknya terhadap perkembangan anak sebagai generasi penerus bangsa, serta penanganan dan pencegahan stunting. Kegiatan penyuluhan dilakukan dengan sasaran keluarga penderita stunting, kader posyandu, ibu hamil, perangkat desa dan beberapa perwakilan masyarakat. Indikator keberhasilan kegiatan ini adalah adanya peningkatan pengetahuan tentang stunting dan upaya pencegahannya dan diharapkan muncul kesadaran akan bahaya yang dapat ditimbulkan akibat stunting.

\section{Pelatihan}

Kegiatan pelatihan dilakukan beberapa kali dengan topik yang berbeda-beda, yaitu pelatihan kader siaga stunting, pelatihan pembuatan sistem pertanian hidroponik dan pelatihan penyiapan dan pembuatan menu sehat. Pelatihan kader siaga stunting ditujukan untuk para kader posyandu, keluarga penderita dan perwakilan masyarakat. Indikator keberhasilan kegiatan ini adalah terbentuk kader siaga stunting. Upaya 
tindak lanjut yang dapat dilakukan adalah mengevaluasi peran kader dalam menangani masalah stunting.

Pelatihan lain yang diberikan adalah pelatihan pembuatan sistem penanaman hidroponik. Sasaran kegiatan ini adalah keluarga penderita sunting, kader posyandu, ibu rumah tangga, perangkat desa dan perwakilan masyarakat. Kegiatan ini dimaksudkan agar masyarakat Desa Sukogidri umumnya dan keluarga penderita stunting dapat memenuhi kebutuhan gizi penderita secara lebih ekonomis, artinya dapat menyediakan sendiri tanpa harus membeli. Indikator keberhasilan kegiatan adalah sasaran dapat melakukan pertanian hidroponik. Sebagai tindak lanjut yang dilakukan adalah mengevaluasi pemanfaatan penanaman secara hidroponik oleh sasaran.

Topik pelatihan yang juga diberikan adalah pelatihan penyiapan dan pembuatan menu sehat. Sasaran kegiatan ini adalah keluarga penderita stunting, kader posyandu, ibu rumah tangga dan perwakilan masyarakat. Indikator kegiatan adalah sasaran dapat menyiapkan menu sehat untuk keluarganya, tertama dalam hal ini adalah penderita stunting.

\section{Pemberian Makanan Sehat}

Kegiatan pemberian makanan tambahan ditujukan untuk penderita stunting, ibu hamil, ibu menyusui dan kelompok rentan gizi. Makanan yang diberikan adalah menu makanan sehat empat sehat lima sempurna. Dengan kegiatan ini diharapkan sasaran mengetahui contoh makanan sehat sehingga nanti lebih mudah untuk memilih terutama menggunakan bahan-bahan yang ada di sekitar.

\section{HASIL DAN PEMBAHASAN}

\section{Status gizi dan status kesehatan}

Pengukuran status gizi anak dilakukan pada 43 balita yang berasal dari seluruh dusun yang ada di Desa Sukogidri, Jember, meskipun jumlah ini bukan jumlah keseluruhan balita yang ada di Desa Sukogidri. Sebanyak 22 balita laki-laki dan 21 balita perempuan. Data antropometri yang dikumpulkan adalah tinggi badan (TB), berat badan (BB), lingkar perut, lingkar lengan atas dan lingkar kepala. Ditemukan 13 dari 43 anak (30\%) balita diketahui menderita stunting. Angka ini cukup tinggi, karena pemeriksaan dilakukan bersama-sama dengan kegiatan posyandu yang lebih sering diikuti oleh penderita stunting. Pada pengukuran yang dilakukan tahun 2018, jumlah total penderita stunting di Desa Sukogidri sebanyak 18 orang.

Pemeriksaan status gizi dan kesehatan juga dilakukan pada ibu hamil dan calon ibu. Didapatkan 11 ibu hamil dan 48 orang calon ibu yang diperiksa. Pemeriksaan yang dilakukan meliputi usia, berat badan (BB), tinggi badan (TB), lingkar perut, lingkar lengan atas (LLA), tekanan darah, denyut nadi, dan kadar gula darah. Usia ibu hamil antara 19 - 41 tahun, dengan tekanan darah normal antara 110-120/ 60-80 mmHg. Sedangkan kadar gula darahnya 6 dari 11 orang ibu hamil berada di bawan $100 \mathrm{mg} / \mathrm{dl}$ dan tidak ada ibu hamil dengan kadar gula darah lebih dari $140 \mathrm{mmHg}$. Ibu hamil merupakan kelompok yang renan permasalahan gizi. Seperti diketahui bahwa banyak 
faktor yang menyebabkan stunting, dimulai dari permasalahan gizi yang dialami oleh calon ibu, dilanjutkan dengan ibu hamil yang juga mempunyai masalah. Permasalahan kronik yang terjadi adalah asupan gizi yang tidak memadai dan kemungkinan rentan terhadap infeksi, sehingga sering sakit.

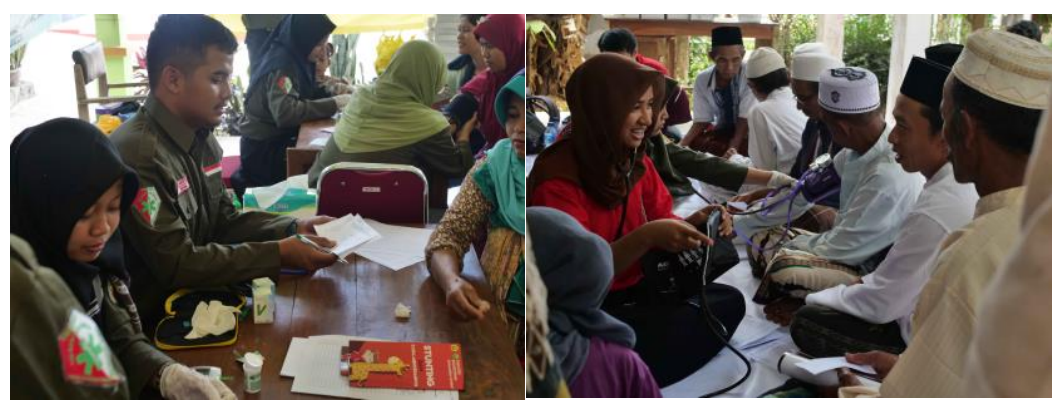

Gambar 1. Pemeriksaan status gizi dan kesehatan

Kegiatan pengukuran status kesehatan usia produkif dan lansia ini diikuti oleh 20 orang petani laki-laki dan 16 orang perempuan. Pemeriksaan kesehatan yang dilakukan meliputi pengukuran data dasar seperti umur, jenis kelamin, dilanjutkan dengan pengukuran berat badan (BB), tinggi badan (TB), lingkar perut, lingkar lengan atas, tekanan darah, denyut nadi, kadar gula darah acak dan asam urat. Sebanyak 5 orang mempunyai indeks masa tubuh (IMT) overweight, 5 orang obesitas, dan 1 orang underweight. Sebanyak 20 orang (55,5\%) ditemukan mempunyai tekanan darah tinggi (baik pre hipertensi, hipertensi grade 1 dan hipertensi grade 2). Sebanyak 5 orang ditemukan memepunyai kadar gula darah yang tinggi (prediabetes dan diabetes mellitus), dan 19 orang (52,8 \%) mempunyai kadar asam urta yang tinggi (hiperurisemia). Penduduk yang ditemukan mempunyai status kesehatan tidak normal disarankan ke puskesmas untuk mendapat pemeriksaan dan pengobatan lebih lanjut. Terjadinya stunting sebagai suatu proses yang kronik dan kompleksitas permasalahan stunting memerlukan penanganan yang terintegrasi dan melibatkan beberapa sektor, antara lain sektor ekonomi, oleh karena itu pengukuran status kesehatan masyarakat usia produktif juga perlu dilakukan agar mendapat gambaran kondisi kesehatannya. Usia produktif sebagai komponen pencari sumber ekonomi utama tentu sangat berperan dalam menangani masalah stunting.

\section{Penyuluhan}

Penyuluhan kesehatan merupakan kegiatan yang sangat erat pada upaya kesehatan. Penyuluhan kesehatan dilakukan dalam rangka mengubah perilaku seseorang atau kelompok masyarakat agar hidup sehat. Teknik yang digunakan adalah komunikasi, informasi, dan edukasi. Tujuan penyuluhan dalah memberdayakan individu, kelompok, dan masyarakat dalam rangka memelihara, meningkatkan, dan melindungi kesehatan melalui peningkatan pengetahuan, kemauan dan kemampuan, serta mengembangkan kondisi yang mendukung yang dilakukan dari, oleh, dan untuk masyarakat sesuai dengan sosio budaya setempat (Undang-Undang RI, 1992).

Kegiatan penyuluhan tentang stunting diikuti oleh 70 orang peserta yang terdiri dari perangkat desa, tenaga kesehatan desa, kader posyandu, tokoh masyarakat, ibu-ibu yang mempunyai balita, ibu hamil dan calon ibu. Peserta diberi informasi yang lengkap 
tentang pengertian stunting dan disadarkan tentang bahaya yang ditimbulkan akibat stunting. Stunting bukan hanya mempengaruhi ukuran atau tinggi badan anak, tetapi juga dapat mempengaruhi kecerdasan karena menghambat perkembangan otak dan fisik, menimbulkan kegemukan sehingga rentan mengidap berbagai penyakit termasuk penyakit tidak menular. Pada saat dewasa, penderita stunting juga dapat mengakibatkan prestasi yang kurang bagus. Oleh karena itu, stunting bukan hanya masalah ringan, tetapi merupakan masalah besar yang perlu dipecahkan secara bersama-sama. Selain itu kepada peserta juga disampaikan tentang pencegahan dan penanganan stunting. Termasuk pentingnya 1000 hari pertama kehidupan sebagai upaya mencegah stunting (Direktorat Jenderal Bina Kesehatan Masyarakat. Direktorat Bina Gizi Masyarakat. Departemen Kesehatan. (2007).

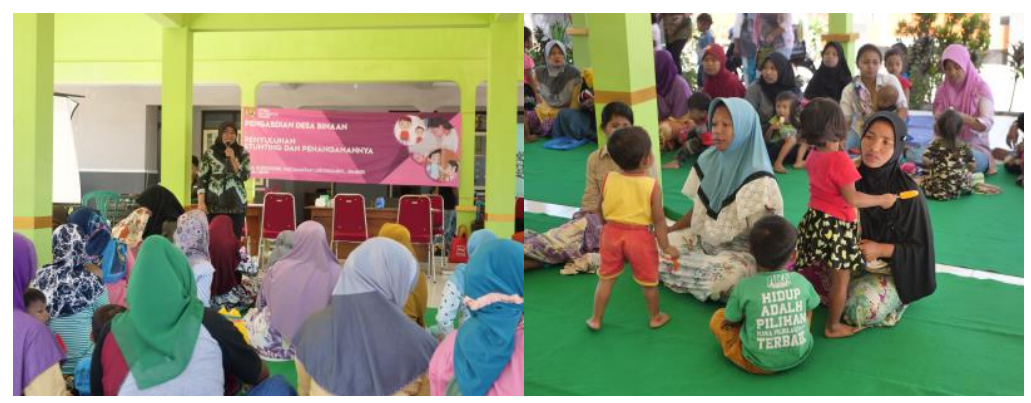

Gambar 2. Penyuluhan kesehatan

Peserta sangat antusias mengikuti kegiatan ini, hal ini terlihat dari pertanyaanpertanyan yang muncul dari peserta saat sesi tanya jawab. Selain itu, kepada peserta yang menyampaikan pertanyaan diberikan hadiah sehingga memancing keaktifan peserta untuk bertanya. Hadiah juga diberikan kepada peserta dapat menjawab pertanyaan yang disampaikan oleh tim pengabdian terkait materi penyuluhan saat itu, yaitu tentang stunting dan penanganannya.

\section{Pelatihan dan Pemberian Makanan Sehat}

Pelatihan kader siaga stunting diikuti oleh kader posyandu yang ada di Desa Sukogidri, Jember. Ada 10 orang dari total 20 orang (50\%) kader posyandu yang mengikuti keseluruhan kegiatan pelatihan siaga stunting. Kader dibekali khusus materi-materi tentang stunting, pendekatan yang dilakukan untuk penanganan dan pencegahan stunting serta dampak jangka pendek dan jangka panjang stunting. Di akhir kegiatan, kader yang telah selesai mengikuti pelatihan diberi sertifikat sebagai kader siaga stunting. Kegiatan ini dilakukan juga dengan melibatkan bidan desa dan perawat yang ada di Desa Sukogidri, Jember.

Pada program pengabdian kepada masyarakat ini, juga dilakukan kegiatan pelatihan tentang sistem pertanian hidroponik dengan sasaran perangkat desa, kader posyandu, tokoh masyarakat, petani dan ibu-ibu sejumlah 60 orang. Pada pelatihan ini diajarkan bagaimana caranya bercocok tanam dengan sistem hidroponik dengan alatalat sederhana yang mudah didapatkan di sekitar rumah penduduk. Selain itu, juga diberikan contoh-contoh tanaman yang dapat dipilih, yang mempunyai nilai gizi yang tinggi serta mempunyai nilai ekonomi yang baik. Karena tujuan ke depan, hasil pertanian hidroponik ini bukan hanya untuk konsumsi sendiri dalam rangka 
memenuhi kebutuhan gizi keluarga, tetapi juga dapat digunakan sebagai tambahan penghasilan. Sistem pertanian hidroponik dapat menjadi alternatif pertanian yang meminimalkan penggunaan pestisida. Sistem pertanian ini juga digunakan untuk mendukung kegiatan pencegahan stunting dengan menyediakan bahan pangan yang bervariasi dan mempunyai nilai gizi yang baik guna mendukung gerakan pemberian makanan yang bervariasi. Seperti disampaikan Kementerian Kesehatan bahwa permasalahan stunting bukan hanya masalah ekonomi, tetapi juga pola asuh yang juga melibatkan ketersediaan bahan pangan yang sesuai kebutuhan gizi. Dalam buku saku desa penanganan stunting, Kementerian Desa, Pembagunan Daerah Tertinggal, dan Transmigrasi (2017), juga telah melakukan pendekatan-pendekatan multisektoral yang dapat dilakukan untuk menangani masalah stunting antara lain melibatkan partisipasi masyarakat dengan menggunakan dana desa yang tersedia.

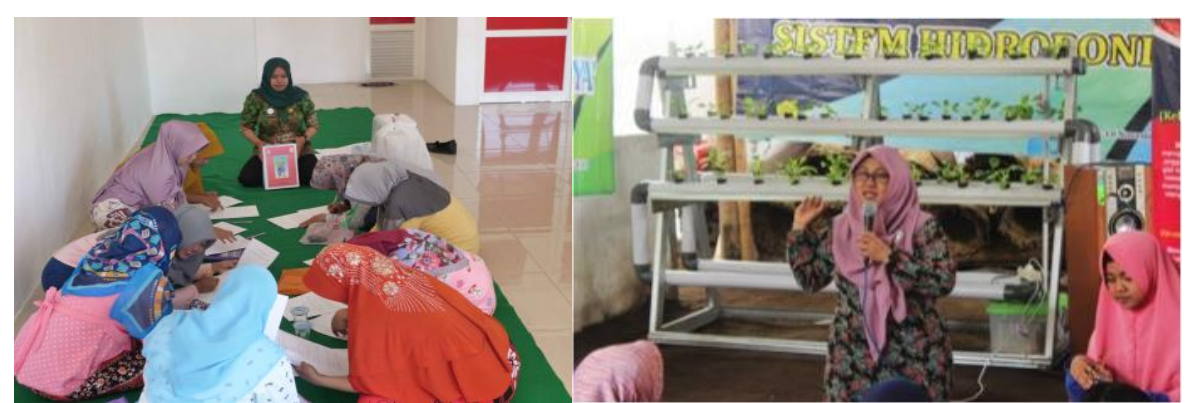

Gambar 3. Pelatihan kader siaga stunting dan penanaman sistem hidroponik

Kegiatan pelatihan berikutnya adalah pelatihan menyiapkan dan memasak makanan yang sehat serta memenuhi kebutuhan gizi anak. Menu sehat yang ditunjukkan adalah menu 4 sehat 5 sempurna meliputi nasi atau jagung, lauk pauk, sayur, dan buah serta dilengkapi susu. Kepada peserta dan anaknya diberikan contoh langsung menu sehat yang baik dikonsumsi untuk anak-anak. Selain itu juga ditekankan pentingnya variasi menu yang diberikan dengan bahan-bahan (lauk, sayur atau buah yang mudah didapatkan di sekitar rumah penduduk dan harganya tidak mahal. Pelatihan ini diikuti oleh 59 peserta ibu-ibu beserta anaknya. Kegiatan pelatihan pembuatan menu sehat langsung dilanjutkan dengan pemberian makanan tambahan sebagai contoh langsung menu sehat yang baik dikonsumsi anak.

\section{SIMPULAN}

Program penanganan dan pencegahan stunting yang telah dicanangkan pemerintah perlu dukungan berbagai pihak dalam hal implementasinya, baik akademisi maupun masyarakat. Upaya peningkatan kesadaran dan pengetahuan masyarakat akan stunting dan dampaknya serta upaya pencegahan dan penanganan stunting perlu terus dilakukan dalam pemberdayaan masyarakat untuk mempercepat mengatasi masalah stunting. 


\section{REFERENSI}

Aridiyah, F.O., Rohmawati, N., \& Ririanty, M. (2015). Faktor-faktor yang mempengaruhi kejadian sunting pada anak balita di wilayah pedesaan dan perkotaan. e-Journal Pustaka Kesehatan, 1 (1), 163-170.

Desa Sukogidri. (2017). Profil Desa Sukogidri Kecamatan Ledokombo Kabupaten Jember. Jember: Pemerintah Desa Sukogidri.

Kementerian Kesehatan Republik Indonesia. (2018). Cegah stunting dengan perbaikan pola makan pola asuh dan sanitasi (2). Retrieved May 22, 2019 from www.depkes.go.id/article/view/18040700002/cegah-stunting-dengan-perbaikanpola-makan-pola-asuh-dan-sanitasi-2-html

Departemen Kesehatan. (2007). Pedoman Strategi KIE Keluarga Sadar Gizi (KADARZI). Jakarta: Direktorat Jenderal Bina Kesehatan Masyarakat. Direktorat Bina Gizi Masyarakat. Departemen Kesehatan

Dinas Kesehatan Pemerintah Kabupaten Jember. (2018). Kemenkes support Jember komitmen turunkan angka balita stunting. Retrieved May 22, 2019 from www.jember.go.id/kemenkes-support-jember-komitmen-turunkan-angka-balitastunting/

Kementerian Desa, Pembagunan Daerah Tertinggal, dan Transmigrasi. (2017). Buku saku desa dalam penanganan stunting. Jakarta: Kementerian Desa, Pembagunan Daerah Tertinggal, dan Transmigrasi

Komisi Ilmiah Badan Litbang Kesehatan. (2013). Rancangan Agenda Riset Kesehatan Nasional 2013-2018. Rapat Kerja Badan Penelitian Pengembangan Kesehatan. Jakarta: Komisi Ilmiah Badan Litbang Kesehatan.

Kementerian Kesehatan RI. (2018). Situasi Balita Pendek (Stunting) di Indonesia. Jakarta: Pusat Data dan Informasi Kementerian Kesehatan RI.

Undang-Undang Republik Indonesia No.23 tahun 1992 tentang Kesehatan. Jakarta.

WHO. (2019). Sustainable Development Goals. Retrieved September 15, 2019 from https://www.who.int/sdg/en/

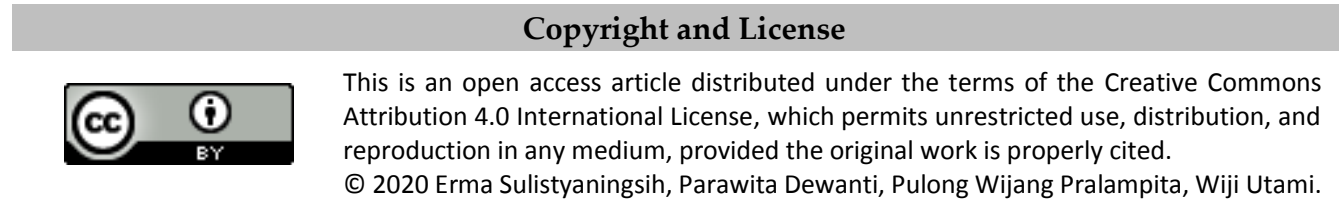

Published by LP3M of Universitas Mathla'ul Anwar Banten in collaboration with the Asosiasi Jurnal Pengabdian Kepada Masyarakat (AJPKM) 